\title{
Promotion of $\beta$-catenin/Foxo1 signaling ameliorates renal interstitial fibrosis
}

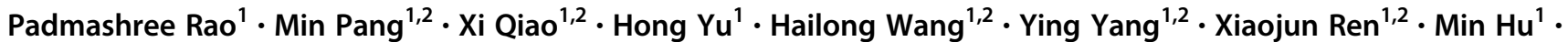 \\ Titi Chen ${ }^{1}$ - Qi Cao ${ }^{1}$ - Yiping Wang ${ }^{1} \cdot$ Matloob Khushi ${ }^{3,4}$. Geoff Zhang ${ }^{5}$ Yuan Min Wang ${ }^{5}$. Chow Heok P'ng $^{6}$. \\ Brian Nankivell ${ }^{6} \cdot$ Vincent W. Lee $^{1,6} \cdot$ Stephen I. Alexander $^{5} \cdot$ Guoping Zheng $^{1} \cdot$ David C. Harris $^{1,6}$
}

Received: 2 June 2018 / Revised: 12 April 2019 / Accepted: 1 May 2019 / Published online: 26 June 2019

(c) The Author(s), under exclusive licence to United States and Canadian Academy of Pathology 2019. This article is published with open access

\begin{abstract}
Transforming growth factor $\beta$ (TGF- $\beta$ ) is the key cytokine involved in causing fibrosis through cross-talk with major profibrotic pathways. However, inhibition of TGF- $\beta$ to prevent fibrosis would also abrogate its anti-inflammatory and wound-healing effects. $\beta$-catenin is a common co-factor in most TGF- $\beta$ signaling pathways. $\beta$-catenin binds to T-cell factor (TCF) to activate profibrotic genes and binds to Forkhead box $\mathrm{O}$ (Foxo) to promote cell survival under oxidative stress. Using a proximity ligation assay in human kidney biopsies, we found that $\beta$-catenin/Foxo interactions were higher in kidney with little fibrosis, whereas $\beta$-catenin/TCF interactions were upregulated in the kidney of patients with fibrosis. We hypothesised that $\beta$-catenin/Foxo is protective against kidney fibrosis. We found that Foxo1 protected against rhTGF- $\beta 1$ induced profibrotic protein expression using a CRISPR/cas9 knockout of Foxo1 or TCF1 in murine kidney tubular epithelial C1.1 cells. Co-administration of TGF- $\beta$ with a small molecule inhibitor of $\beta$-catenin/TCF (ICG-001), protected against kidney fibrosis in unilateral ureteral obstruction. Collectively, our human, animal and in vitro findings suggest $\beta$-catenin/ Foxo as a therapeutic target in kidney fibrosis.
\end{abstract}

\section{Introduction}

Kidney fibrosis is characterized by over-production and deposition of extracellular matrix and is considered to be a crucial factor in driving chronic kidney disease (CKD) towards kidney failure $[1,2]$. There is currently no effective

Supplementary information The online version of this article (https:// doi.org/10.1038/s41374-019-0276-z) contains supplementary material, which is available to authorized users.

Guoping Zheng

guoping.zheng@sydney.edu.au

1 Centre for Transplantation and Renal Research, The University of Sydney at The Westmead Institute for Medical Research, Sydney, Australia

2 Shanxi Medical University, Taiyuan, China

3 Children's Medical Research Institute, The University of Sydney, Sydney, Australia

4 School of IT, The University of Sydney, Sydney, Australia

5 Children's Hospital at Westmead, Sydney, Australia

6 Westmead Hospital, Sydney, Australia treatment targeting kidney fibrosis. Transforming growth factor $\beta$ (TGF- $\beta$ ) plays an important role in the development of tissue fibrosis [3]. However, the inhibition of TGF- $\beta$ to prevent fibrosis would also abrogate its anti-inflammatory and wound-healing effects $[4,5]$. The contrasting effects of TGF- $\beta$ (profibrotic versus anti-inflammatory) have posed a considerable challenge in the treatment of fibrotic diseases affecting the kidneys and other organs. However, we have recently described the role of $\beta$-catenin/Foxo in the redirection of TGF- $\beta$ signaling from an undesirable profibrotic to a beneficial anti-inflammatory function [6].

$\beta$-catenin binds to members of the T-cell factor (TCF)/ lymphoid enhancer binding factor in the Wnt signaling pathway. $\beta$-catenin/TCF is central to all the profibrotic pathways, including TGF- $\beta /$ Smad, integrin/ILK, and $\mathrm{Wnt} / \beta$ catenin pathways [7-9]. In addition, $\beta$-catenin also binds to Forkhead box O (Foxo) proteins that belong to the Forkhead family of transcription factors, which play important roles in the control of cell differentiation, proliferation, and survival [10]. The role of Foxo proteins in the regulation of cell survival has been described by Greer and Brunet [11].

Both TCF and Foxo bind to the armadillo repeats $1-7$ on $\beta$-catenin [12]. $\beta$-catenin, in turn, may play a dual role, 
depending on its binding to either TCF or Foxo. $\beta$-catenin promotes fibrosis through its interactions with TCF, while its interactions with Foxo transcription factors may inhibit the $\beta$-catenin/TCF functions [13, 14]. In a previous study, we found that ICG-001, a small molecule inhibitor, prevented $\beta$-catenin/TCF interaction, shifting $\beta$-catenin towards Foxo binding, thereby reducing the $\beta$-catenin/ TCF-mediated profibrotic effects of TGF- $\beta$ while enhancing the $\beta$-catenin/Foxo-mediated anti-inflammatory effects [6]. However, whether $\beta$-catenin/Foxo protects against the profibrotic effects of TGF- $\beta$ remains unknown.

In the current study, we examined $\beta$-catenin/Foxo and $\beta$-catenin/TCF interactions using human kidney biopsies from patients with CKD due to diabetic nephropathy, hypertensive nephropathy, IgA nephropathy, focal segmental glomerulosclerosis (FSGS), mesangiocapillary glomerulonephritis (MCGN), medullary cystic diseases, as well as from patients following a kidney transplant. The effect of $\beta$-catenin/Foxo interaction versus $\beta$-catenin/TCF on TGF- $\beta$-induced profibrotic changes was examined in tubular epithelial cells in vitro by CRISPR/cas9-mediated knockout of Foxo1 or TCF1 and in a kidney fibrosis model, unilateral ureteric obstruction (UUO). We showed that the binding of $\beta$-catenin to Foxo protected against TGF- $\beta$-induced profibrotic effects and ameliorated kidney fibrosis.

\section{Materials and methods}

\section{Human kidney biopsies}

Paraffin-embedded human kidney biopsies from patients with thin basement membrane nephropathy ( $0-5 \%$ fibrosis score, considered as "kidney biopsies with little fibrosis"), diabetic nephropathy, kidney transplant, hypertensive nephropathy, IgA nephropathy, and other kidney diseases were obtained from the Department of Anatomical Pathology, Westmead Hospital. The study of human kidney tissue was approved by the Human Research Ethics Committee of Western Sydney Local Health District (WSLHD).

\section{Cell cultures}

Mouse tubular epithelial C1.1 cells [15] (a kind gift from the laboratory of Dr Rudolf Wuthrich, Switzerland) were cultured in DMEM:HAM's F12 $(1: 1 \mathrm{v} / \mathrm{v})$ medium (Invitrogen) containing $1 \mathrm{M}$ HEPES (Invitrogen), MEM NEAA (Invitrogen), $5 \mathrm{mg} / \mathrm{ml}$ insulin (Sigma), $1.25 \mathrm{ng} / \mathrm{ml}$ prostaglandin E1 (Cayman Chemicals, Ann Arbor, MI), 0.0338 $\mathrm{ng} / \mathrm{ml}$ 3,3,5- triiodothyronine (Sigma), $5 \mathrm{mg} / \mathrm{ml}$ hydrocortisone (Sigma), $1.73 \mathrm{ng} / \mathrm{ml}$ transferrin (Sigma), $18 \mathrm{ng} / \mathrm{ml}$ sodium selenite (Sigma), and 5\% fetal bovine serum (FBS) (Sigma-Aldrich) at $37{ }^{\circ} \mathrm{C}$, in $5 \% \mathrm{CO}_{2}$. For treatment of cells, serum-supplemented media were replaced with serum-free media.

\section{Generation of Foxo1 KO cell line and TCF1 KO cell line by CRISPR/cas9}

To generate Foxo1 KO C1.1 cell lines, we co-transfected Foxo1 CRISPR/cas9 KO plasmid with a Foxo1 HDR plasmid (Santa Cruz Biotechnology, Inc), following the manufacturer's instructions. In brief, $\mathrm{C} 1.1$ cells were transfected and incubated for $24 \mathrm{~h}$ under conditions normally used to culture the cells. Media were replaced $24 \mathrm{~h}$ post-transfection. Puromycin antibiotic $(2 \mu \mathrm{g} / \mathrm{ml})$ was added after two passages of the cells to allow for positive selection of transfected cells. Similarly, TCF1 gene was knocked out using TCF1 double nickase plasmid (Santa Cruz Biotechnology, Inc).

KO was verified by Western blot of Foxo1 and TCF1 expression and fluorescence microscopy for the RFP/GFP signal.

\section{Cell treatments}

Subconfluent cultures of control C1.1, Foxo1 KO C1.1, and TCF1 KO C1.1 cells were rinsed with PBS (Invitrogen) and then treated with rhTGF- $\beta 1$ ( $3 \mathrm{ng} / \mathrm{ml}$, Biosource) with or without ICG-001 ( $5 \mu \mathrm{M}$, Sigma). After $48 \mathrm{~h}$ of treatment, cells were washed twice with DPBS (Gibco) and either processed for immunofluorescence microscopy or lysed with cold RIPA buffer (Sigma Aldrich), PMSF (1 $\mathrm{mM}$, Sigma) and protease and phosphatase inhibitor cocktail (Thermo Fisher Scientific). Cell lysates were collected and sonicated for $5 \mathrm{~min}$ thrice, centrifuged at $10,000 \mathrm{rpm}$ for $12 \mathrm{~min}$ at $4{ }^{\circ} \mathrm{C}$, and stored at $-20^{\circ} \mathrm{C}$ until protein analysis was performed. For transfection experiments, C1.1 or TCF KO cells were transiently transfected with F-TrCP-Ecad plasmid by Lipofectamine 2000 (Invitrogen) according to the manufacturer's protocol. F-TrCP-Ecad plasmid was a kind gift from the laboratory of Dr. Feng Cong, USA and this plasmid construct encodes a chimeric protein with the binding domain of E-cadherin fused to the beta-transducin repeat-containing protein $(\beta \operatorname{TrCP})$ ubiquitin-protein ligase [16]. A previous study from our laboratory confirms F-TrCp-Ecad plasmid degrades cytosolic $\beta$-catenin in C1.1 cells [17].

\section{Western blot}

Protein concentrations of lysates were estimated by BCA Protein Assay Kit (Thermo Fisher Scientific). Sample absorbance and protein concentrations were read with a Multilabel Reader Victor TM X3 (Perkin Elmer) using BSA standard curve. 
Western blot samples were prepared by combining NuPAGE LDS sample buffer (Invitrogen), NuPAGE sample reducing agent (Invitrogen), the protein sample, and Millipore water to equate sample volumes. Wells were generally loaded with $30 \mu \mathrm{g}$ of protein. The samples were placed on a $95^{\circ} \mathrm{C}$ heating block for $6 \mathrm{~min}$ to denature proteins and then loaded into $10 \%$ Mini-Protean TGX precast gels (Bio-Rad) with Novex Sharp pre-stained protein standard (Thermo Fisher Scientific). The gel was run at $100 \mathrm{~V}$ for $1 \mathrm{~h} 30 \mathrm{~min}$ by using 10x Tris-Glycine/SDS Buffer (Biorad) and gels were electrotransferred to nitrocellulose using a Transblot turbo Transfer Apparatus (Biorad). The membrane was blocked by 5\% Skim milk in PBS at room temperature for $1 \mathrm{~h}$ and incubated with primary antibodies [anti-collagen I (1:1000; Abcam), anti-collagen III (1:1000, Abcam), anti-collagen IV (1:1000, Abcam), anti-N-cadherin, anti-vimentin (1:1000; Cell Signalling), anti- $\beta$ catenin $\left(1: 1000\right.$, BD Biosciences) overnight at $4{ }^{\circ} \mathrm{C}$ in $5 \%$ skim milk diluted in PBST (Phosphate buffered saline with $0.1 \%$ Tween 20). After washes in PBST, horseradish peroxidase-conjugated secondary antibodies (1:2000) (Cell signaling) were incubated at room temperature for $1 \mathrm{~h}$. Membranes were washed in PBST and developed using standard chemiluminescence with ECL (Advansta) and exposure to Chemi DocTM MP Imaging System (Biorad). To account for loading variability, all protein bands were normalized to $\beta$-actin or $\alpha$-tubulin.

\section{Co-immunoprecipitation}

Co-immunoprecipitation (Co-IP) was performed according to the instructions on the Dynabeads ${ }^{\circledR}$ Protein $G$ kit (Thermo Fisher Scientific). In brief, C1.1 cell lysates were extracted and then quantified using Pierce ${ }^{\mathrm{TM}}$ BCA Protein Assay Kit (Thermo Fisher Scientific). Co-IP was carried out with $\beta$-catenin $(2 \mu \mathrm{g}$, BD Biosciences) or control IgG (Cell signalling) and bound to Dynabeads (Dynabeads- $\mathrm{Ab}$ ). Between 400-600 $\mu \mathrm{g}$ of protein were incubated overnight at $4{ }^{\circ} \mathrm{C}$ with the antibody (Dynabeads-Ab-Ag complex). The dynabeads were collected by Magnet Rack (Biorad). The supernatant was discarded and Dynabeads-Ab-Ag complex was washed and was eluted by boiling with premixed NuPAGE $^{\circledR}$ LDS Sample Buffer and NuPAGE ${ }^{\circledR}$ Sample Reducing Agent (Thermofischer Scientific). The supernatant (bound proteins) were subjected to Western blot.

\section{Proximity ligation assay (Duolink)}

Proximity ligation assay (PLA) experiments were performed on $\mathrm{C} 1.1$ cells (grown in a four-well chamber slide system), paraffin-embedded mouse kidney sections and human kidney biopsies and analysed using the DUOLink kit (Sigma-Aldrich) according to the manufacturer's instructions. Briefly, either cells or deparaffinized tissues were fixed with $4 \%$ paraformaldehyde (Sigma) in PBS for 10 min and permeabilized with $0.5 \%$ Triton X-100 (Sigma) in PBS and blocked with blocking solution for $1 \mathrm{~h}$ at RT, then incubated with the primary antibodies, anti-mouse $\beta$-catenin (BD Transduction Laboratories) and anti-rabbit Foxo1 (Cell signaling) or anti-mouse $\beta$-catenin and antirabbit TCF1 (Cell signaling). Negative controls were obtained by omitting one of the primary antibodies. Secondary antibodies tagged with short DNA oligonucleotides were added. Hybridization, ligation and amplification were performed. Each slide was mounted with PLA mounting reagent containing DAPI and fluorescent spots visualized by confocal microscope and were counted by using Otsu thresholding Matlab software [18]. The number of PLA spots/100 nuclei was quantified in multiple [5-8] microscopic fields (in tubular cell fields), averaged, and then used for statistical analysis.

\section{Foxo reporter assay}

C1.1 cells were transfected using Cignal Foxo reporter kit from Qiagen with or without $1 \mu \mathrm{g}$ F-TrCP-Ecad plasmid. After $24 \mathrm{~h}$ of treatment, cells were lysed and Firefly and Renilla luciferase activities were assessed using Dual-Glo luciferase assay system (Promega) by a luminometer (Wallac 1420 Victor Plate Reader, Perkin Elmer Life Sciences). The Firefly luciferase output was normalized against Renilla luciferase output.

\section{TOP-flash assay}

TOP-flash assay was performed as stated previously [17] in short, C1.1 cells were transfected with Top-flash or its mutant control FOP-flash at $1 \mu \mathrm{g} / \mathrm{well}$ and with pRL-RSV Renilla luciferase plasmid ( $0.1 \mu \mathrm{g} / \mathrm{well})$ (Qiagen) as an internal control for transfection efficiency. After $12 \mathrm{~h}$, cells were treated with TGF- $\beta 1(3 \mathrm{ng} / \mathrm{ml})$ and/or ICG-001 (5 $\mu \mathrm{M})$. Cells were lysed, and luciferase activities were measured using a Dual-Glo luciferase assay system (Promega) in Wallac 1420 Victor Plate Reader. Relative luciferase activities were measured as the ratio of TOP-flash/FOPflash luciferase activity, each normalized against Renilla luciferase activity. The mean values of the normalized ratios were compared.

\section{UUO model and treatment}

Male Foxp $3^{\text {gfp }}$ (Ly5.1) mice were a generous gift of Tim Sparwasser [19]. Male mice aged 8-10 weeks were used in all experiments. All mice were acquired from the specific pathogen-free laboratory Animal Care Centre of Westmead Hospital. 
UUO was induced by ligation of the left ureter according to an established protocol described previously [20]. UUO and control mice were treated with rhTGF- $\beta 1(50 \mu \mathrm{g} / \mathrm{kg}$ intraperitoneally) second daily or vehicle, with or without ICG-001 (5 mg/kg intraperitoneally) daily after surgery. Dose was selected according to previously published studies $[6,8]$. Our previous study showed that administration of rhTGF- $\beta$ and ICG-001 is effective and safe [6]. Mice were monitored daily and were sacrificed at 14 days after the operation. Kidneys were collected for the assessment of kidney fibrosis by western blot and immunostaining.

\section{Immunohistochemical and immunofluorescence staining}

For human kidney biopsies, the percentage of kidney fibrosis was assessed by a pathologist (CP) blinded to patient identification on the basis of Masson trichrome staining. The stained slides were scanned by Aperio scan scope and quantified using Image $\mathbf{J}$ by a blinded observer.

For immunofluorescence staining, deparaffinized slides were used. Initially, slides were deparaffinized and fixed with methanol and acetone at 1:1 volume. This was followed by heat antigen retrieval using sodium citrate buffer and then blocked with 2\% BSA (Sigma) in PBS. Kidney sections were incubated with anti-collagen I (Abcam), anti-collagen III (Abcam), anti-collagen IV (Abcam), antiFoxo1 (Cell signalling) or anti- $\beta$-catenin (BD Transduction Laboratories). To visualize the primary antibodies, sections were stained with Goat anti-rabbit Alexa Fluor 568 (ThermoFisher Scientific). Samples were stained with 4', 6-diamidino-2 phenylindole (DAPI) (Sigma) to visualize the nuclei and mounted with mounting medium (Sigma-Aldrich) and viewed with a DeltaVision Elite Microscope by observers blinded to sample identification.

\section{Fluorescence microscopy}

Except for PLA (duo-link) of cells and animal tissues, imaging was performed by using a DeltaVision Elite Microscope comprising a wide-field inverted epifluorescence microscope (Olympus IX-71), Olympus 60X oil objective (PlanAPO, NA 1.42) and a CoolsSnapHQ2 (Roper Scientific) camera. Deconvolution (conserved ratio method) and other image processing were performed using SoftWoRx Suite 2.0 (Applied Precision, GE) and figures were built using Illustrator (Adobe Systems Inc., USA).

PLA images were acquired by Olympus FV 1000 confocal laser scanning microscope using Olympus IX-81 with an Olympus 60X Oil objective (UPLSAPO, NA 1.35). FV10-ASW 1.7 software was used to acquire the images. Image $\mathbf{J}$ software was used to quantify the images.

\section{Statistical analyses}

All data are presented as mean \pm SEM. Statistical analyses of the data were performed using Graph Pad Prism 7 software. Comparison between groups was made using oneway ANOVA followed by Tukey test. Pearson correlation analysis was used for human data. $P<0.05$ was considered statistically significant.

\section{Study approval}

All mouse studies were carried out in accordance with protocols approved by the Animal Ethics Committee of Western Sydney Local Health District. Formalin sections from human biopsy were obtained from Westmead Hospital and the study was approved by the Human Ethics Committee of Western Sydney Local Health District (approval no LNR/12/WMEAD/114 LNRSSA/12/WMEAD/117). All biopsies were clinically indicated, and only supplementary deidentified tissue was used for research purposes.

\section{Results}

\section{Evidence for $\beta$-catenin/Foxo1 and $\beta$-catenin/TCF1 in human kidney biopsies}

$\beta$-catenin and Foxo1 are well conserved in structure and function between mouse and human. To assess the relevance of this to humans, we first examined the correlation between $\beta$-catenin/Foxo1 or $\beta$-catenin/TCF1 with the severity of kidney fibrosis (Fig. 1a) in kidney biopsies of CKD patients, including those with thin glomerular basement membrane nephropathy (with $0-5 \%$ fibrosis score, considered as "kidney biopsies with little fibrosis"), hypertensive nephropathy, diabetic nephropathy, IgA nephropathy, FSGS, MCGN, medullary cystic diseases and kidney transplant using a PLA. This microscopy technique detects the interactions between two transcription factors [21], in this case, TCF or Foxo with $\beta$-catenin. $\beta$-catenin/TCF1 correlated positively with fibrosis $(r=$ 0.789 in transplant kidney biopsies, $r=0.944$ in diabetic nephropathy, $r=0.919$ in hypertensive nephropathy, $r=$ 0.897 in $\operatorname{Ig}$ A nephropathy, $r=0.653$ in other kidney diseases and $r=0.805$ overall, $P<0.001$ ) while $\beta$-catenin/ Foxo1 correlated negatively with fibrosis $(r=-0.756$ in kidney transplants, $r=-0.794$ in diabetic nephropathy, $r=-0.796$ in hypertensive nephropathy, $r=-0.917$ in IgA nephropathy, $r=-0.743$ in other kidney diseases and $r=-0.730$ overall, $P<0.001$ ) (Fig. 1). These PLA studies showed colocalization of $\beta$-catenin and Foxo1 in tubular cells of kidney biopsies with little fibrosis (thin glomerular basement membrane disease) and colocalization of 

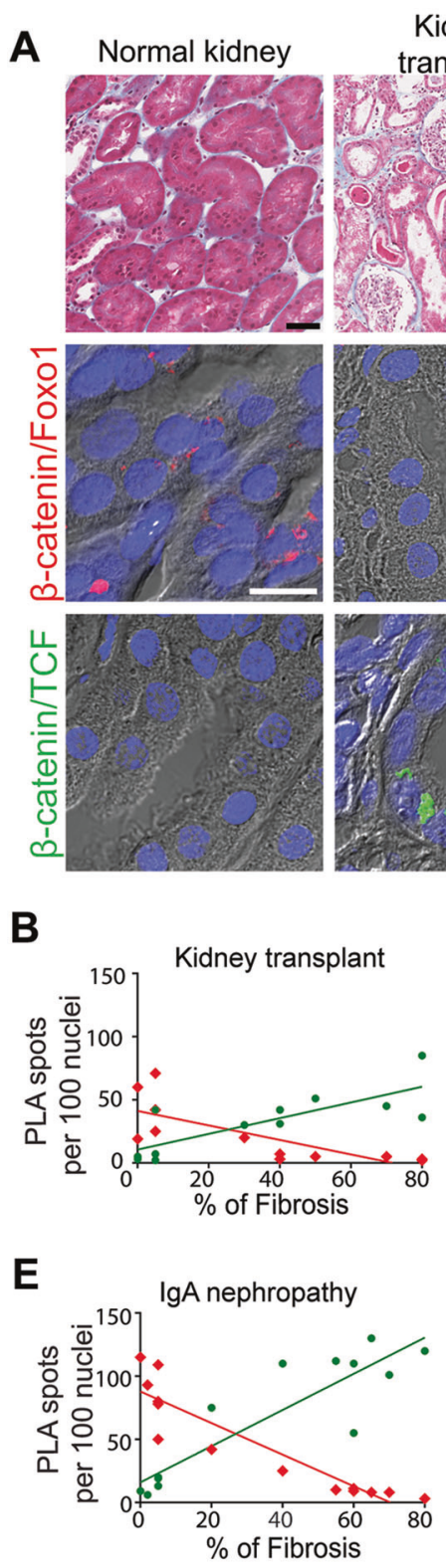
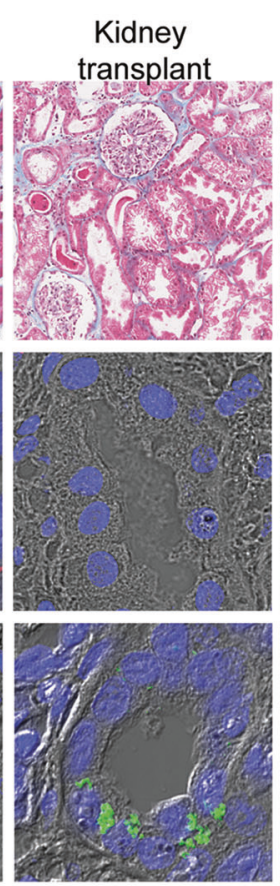

C

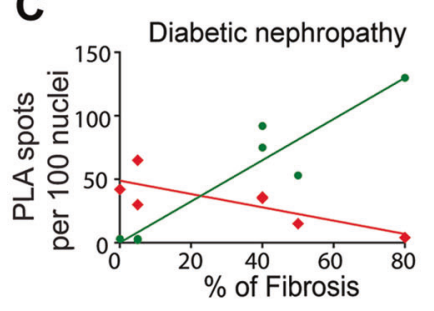

$\mathbf{F}$

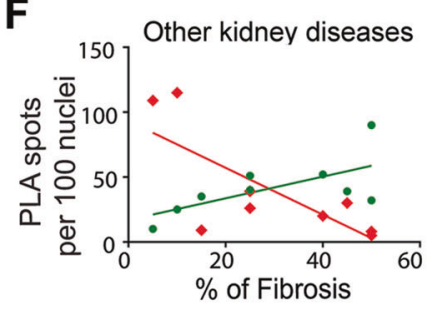

$\lg A$
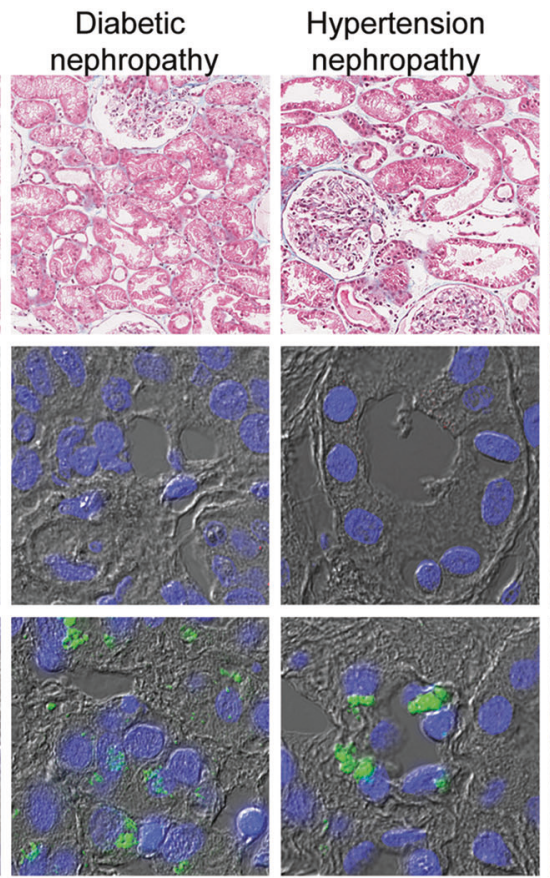
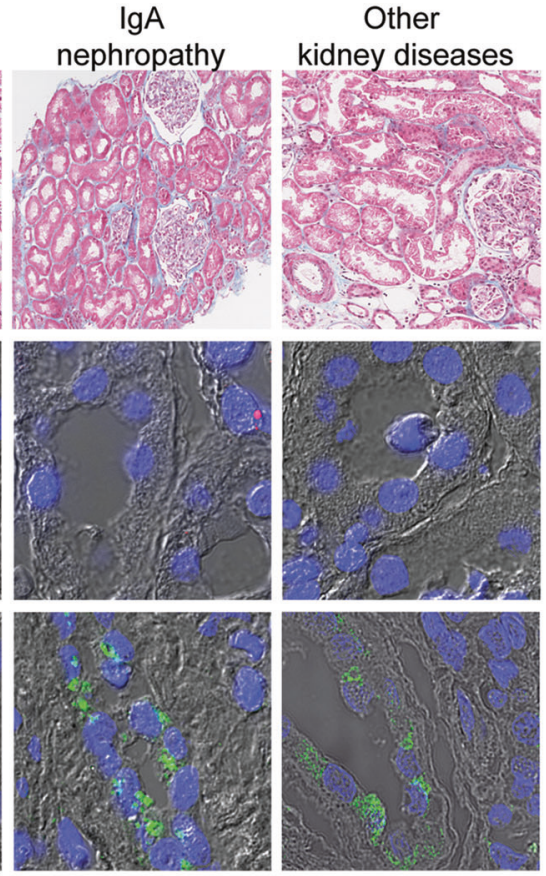
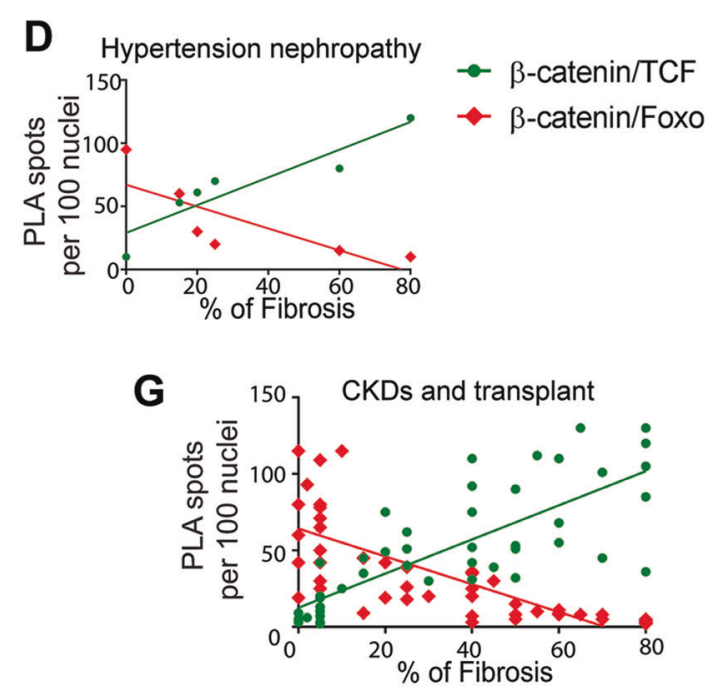

Fig. 1 PLA analysis of $\beta$-catenin/Foxo and $\beta$-catenin/TCF interactions in tubular epithelial cells in human kidney biopsies. a Representative Masson trichrome images (original magnification X20. Scale bar, 10 $\mu \mathrm{m})$ and PLA staining (original magnification X60. Scale bar, $40 \mu \mathrm{m}$ ) of kidney tubular epithelial cells biopsies from humans with multiple kidney diseases and transplant. In the PLA, $\beta$-catenin/Foxo interaction (red spot) was increased in human kidney tubular cells in thin glomerular basement membrane disease, which with a fibrosis score of only $0-5 \%$ was considered as kidney biopsies with little fibrosis ( $n=$ 8) and correlated negatively (red diamonds) with those of b kidney transplant $\left(n=12, r=-0.756^{* *}\right)$, c diabetic nephropathy $(n=7, r=$ $\left.-0.794^{* *}\right)$, d hypertensive nephropathy $\left(n=6, r=-0.796^{*}\right)$, e IgA

nephropathy $(n=14, r=-0.917 * * *)$ and $\mathbf{f}$ other fibrotic kidney biopsies $\left(n=9, \quad r=-0.743^{*}\right)$ whereas $\beta$-catenin/TCF interaction (green spot) correlated positively (green circle) with b kidney transplant $\left(r=0.789^{* *}\right)$, c diabetic nephropathy $(r=0.944 * *)$, d hypertensive nephropathy $(r=0.919 * *)$, e IgA nephropathy $(r=0.897 * * *)$ and $\mathbf{f}$ other fibrotic kidney biopsies $(r=0.653 *)$. $\mathbf{g}$ Overall correlation between $\beta$-catenin/Foxo1 $(r=-0.730 * * *)$ or $\beta$-catenin/TCF $(r=$ $0.805 * * *)$ with $\%$ of fibrosis of all CKD and transplant patient biopsies. b-g Pearson correlation analysis of PLA spots of $\beta$-catenin/Foxo or $\beta$-catenin/TCF versus fibrosis score of the kidney. Results are shown as mean \pm SEM. $* P<0.05$, $* * P<0.01$, $* * * P<0.001$

increased Foxo1 expression and severe fibrosis biopsies showed decreased Foxo1 expression. Kidney biopsies of both little and severe fibrosis score showed $\beta$-catenin expression (Supplemental Fig. 1). 


\section{Redirection of $\beta$-catenin binding from TCF1 to Foxo1 by rhTGF- $\beta 1$ and ICG-001}

To test the binding of $\beta$-catenin to Foxo1, we coimmunoprecipitated Foxo1 or TCF1 with $\beta$-catenin or $\operatorname{IgG}$ (as a control) from murine kidney tubular epithelial cells $(\mathrm{C} 1.1)$ by treating with rhTGF- $\beta 1$ plus either vehicle or ICG-001. The results showed that rhTGF- $\beta 1$ promoted the association of TCF1 with $\beta$-catenin (Fig. 2a). However, the amount of Foxo1 associated $\beta$-catenin was not affected by rhTGF- $\beta 1$ alone. ICG-001 is known to inhibit $\beta$-catenin/ TCF transcription by selectively blocking $\beta$-catenin/CBP interaction [22]. We found here that ICG-001 reduced $\beta$ catenin/TCF binding, while it increased the binding of $\beta$ catenin to Foxo1 in rhTGF- $\beta 1$-treated C1.1 cells (Fig. 2a). This result showed that Foxo competes with TCF1 in binding to $\beta$-catenin in tubular epithelial cells.

To corroborate the observed association of $\beta$-catenin and Foxo through rhTGF- $\beta 1$ and ICG-001 treatment in C1.1, we performed PLA. The cells treated with rhTGF- $\beta 1$ and ICG001 showed a greater number of $\beta$-catenin/Foxo1 interactions (red spots) compared to those of control cells. TGF- $\beta$ alone caused a significant increase in $\beta$-catenin/TCF signal (green) compared to control in C1.1 cells. ICG-001 alone increased $\beta$-catenin/Foxo1 interaction (apparent but not significantly) compared to control, as shown in Fig. 2b, c. However, with both rhTGF- $\beta 1$ and ICG-001, $\beta$-catenin/Foxo1 interaction was increased significantly, indicating a shift of the $\beta$-catenin binding from TCF to Foxo1. Together with co-IP, PLA results showed direct evidence for redirection of $\beta$-catenin binding from TCF to Foxo by rhTGF- $\beta 1$ and ICG-001.

In a functional Foxo reporter assay, treatment with rhTGF$\beta 1$ markedly reduced Foxo-luc activity in C1.1 cells. Conversely, Foxo reporter activity was increased ( 4-fold) when $\beta$-catenin/TCF was inhibited by ICG-001 in the presence of rhTGF- $\beta 1$ (Fig. 2e). However, targeted degradation of $\beta$-catenin by F-TrCP-Ecad plasmid transfection significantly decreased Foxo-luc transcriptional activity in rhTGF- $\beta 1$ and ICG-001 treated C1.1 cells (Fig. 2e). We conclude that $\beta$-catenin is required for Foxo transcriptional activity in C1.1 cells. In a TOP-flash assay used for the detecting $\beta$-catenin/TCF activity, rhTGF- $\beta 1$ treatment significantly increased $\beta$-catenin/TCF activity ( $\sim 3$-fold) in $\mathrm{C} 1.1$ cells. However, rhTGF- $\beta 1$ and ICG-001 reduced the $\beta$-catenin/TCF luciferase activity (Fig. 2f). These results demonstrate that inhibition of $\beta$-catenin/TCF interaction by ICG-001 along with rhTGF- $\beta 1$ significantly increased $\beta$-catenin/Foxo activity.

\section{$\beta$-catenin/Foxo1 protects against rhTGF- $\beta 1$-induced profibrotic protein expression}

Our previous study showed that co-administration of rhTGF- $\beta 1$ and ICG-001 increased $\beta$-catenin/Foxo1-mediated anti-inflammatory effects via Tregs [6]. However, whether $\beta$ catenin/Foxo1 directly protects the tubular epithelial cell against profibrotic changes contributing to kidney fibrosis was not investigated. To address this, we targeted knocked-out Foxo1 and TCF genes using their CRISPR/cas9 KO plasmids in $\mathrm{C} 1.1$ cells (Fig. 3a).

Firstly, we performed CRISPR/cas9-mediated Foxo1 knockout (KO) in C1.1 cells to identify whether Foxo1 protects against expression of a set of proteins associated with fibrosis. Western blot analyses showed that rhTGF- $\beta 1$ treatment induced the expression of collagen I, N-cadherin and vimentin in wild-type C1.1 cells (Fig. 3b, lane 2). The combined treatment of rhTGF- $\beta 1$ and ICG-001 reduced collagen I, N-cadherin and vimentin expression to basal levels (in Fig. 3b, compare lane 3 with lane 2). However, in Foxo1 KO C1.1 cells, the reduction in rhTGF- $\beta 1$-induced collagen I, N-cadherin and vimentin expression by ICG001 treatment was abolished in absence of Foxo1 (in Fig. 3b, compare lane 7 with lane 3), showing a dependence on Foxo1 in ICG-001-mediated reduction of profibrotic changes.

In parallel, we also performed TCF1 $\mathrm{KO}$ in the $\mathrm{C} 1.1$ cell lines using CRISPR/cas9 TCF1 KO plasmid. C1.1 (Wild-Type) and TCF1 KO cells were transiently transfected with F-TrCP-Ecad plasmid to degrade cytosolic $\beta$-catenin. In F-TrCP-Ecad transfected $\mathrm{C} 1.1$ cells, TGF- $\beta 1$-induced collagen I, N-cadherin and vimentin expression was significantly reduced compared to that of rhTGF- $\beta 1$-treated wild-type C1.1 cells (in Fig. $3 \mathrm{c}$, lane 4 compare with lane 3 ), demonstrating a $\beta$-catenindependent profibrotic effect generally believed to be through $\beta$-catenin/TCF. This was confirmed by combined treatment with rhTGF- $\beta 1$ and ICG-001, in which $\beta$-catenin/TCF interaction was inhibited by ICG-001 (Fig. 3c, lane 5). However, inhibition of $\beta$-catenin/TCF interaction by ICG-001 with rhTGF- $\beta 1$ showed a greater reduction of profibrotic protein levels than those seen when $\beta$-catenin was degraded by F-TrCP-Ecad (in Fig. 3c, compare lane 5 with lane 6). In absence of $\beta$-catenin in F-TrCP-Ecad transfected $\mathrm{C} 1.1$ cells, ICG-001 was ineffective in the combined treatment with rhTGF- $\beta 1$ and ICG-001 (in Fig. 3c, compare lane 6 with lane 4). TCF1 KO significantly reduced rhTGF- $\beta 1$-induced expression of collagen I, N-cadherin, and vimentin compared with rhTGF$\beta 1$-treated wild-type $\mathrm{C} 1.1$ cells (in Fig. $3 \mathrm{c}$, compare lane 10 with lane 3 ). $\beta$-catenin is known to bind to either TCF or Foxo in competition [23]. In TCF KO C1.1 cells, $\beta$-catenin uses Foxo as its binding partner. However, degradation of $\beta$-catenin by F-TrCP-Ecad increased the levels of rhTGF- $\beta 1$-induced collagen I, N-cadherin and vimentin (in Fig. 3c, compare lane 10 with lane 11). This result shows that $\beta$-catenin binding to Foxo is required to protects against rhTGF- $\beta 1$-induced profibrotic changes. 
Fig. $2 \beta$-catenin/TCF and $\beta$ catenin/Foxo1 interactions in C1.1 cells. a Representative blots of co-IP for $\beta$-catenin or $\mathrm{IgG}$ (as a negative control) with TCF or Foxo1 in C1.1 cells. RhTGF- $\beta 1$ (3 ng/ml) increased $\beta$-catenin/TCF binding (1st row, 2nd lane) while rhTGF- $\beta 1$ and ICG-001 (5 and $10 \mu \mathrm{M})$ promoted $\beta$-catenin/Foxo1 binding (3rd row, 3rd and 4th lane). Western blots of $\beta$-catenin in $\mathrm{C} 1.1$ cells of control, rhTGF$\beta 1$, rhTGF- $\beta 1+$ ICG-001 $(5 \mu \mathrm{M})$, rhTGF- $\beta 1+$ ICG-001 $(10 \mu \mathrm{M})$, ICG-001 only. Representative of three independent experiments. b Association of $\beta$-catenin/ Foxo1 (red spot) and $\beta$-catenin/ TCF (green spot) were demonstrated by PLA in C1.1 cells. Nuclei were stained with DAPI. Representative of three independent experiments. Original magnification, X60. Scale bar, $10 \mu \mathrm{m}$. c, d Quantitation of PLA spots (fold change) in $\mathrm{C} 1.1$ cells by oneway ANOVA followed by Tukey post hoc test. The relative PLA spots of control were arbitrarily set as one. e The relative Foxo reporter luciferase activities are shown in control C1.1 cells, and F-TrCP-Ecadtransfected, rhTGF- $\beta 1$ treated, rhTGF- $\beta 1$ and ICG-001 treated, F-TrCP-Ecad transfected and rhTGF- $\beta 1$ + ICG-001 treated, ICG-001 alone treated C1.1 cells. f $\beta$-catenin/TCF activity shown by TOP-Flash assay in C1.1 cells with the various treatments described. Data are representative results of at least three independent experiments performed in triplicate. Quantitation of relative luciferase activity is shown as fold increase in luciferase activity. The control was arbitrarily defined as one. Results are shown as mean \pm SEM. $* P<0.05, * * P<0.01$, $* * * P<0.001$
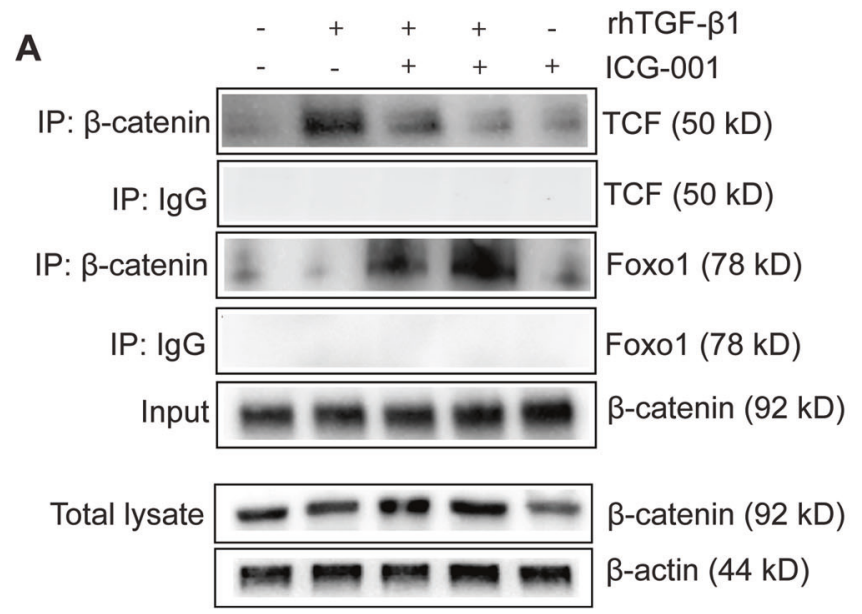

B
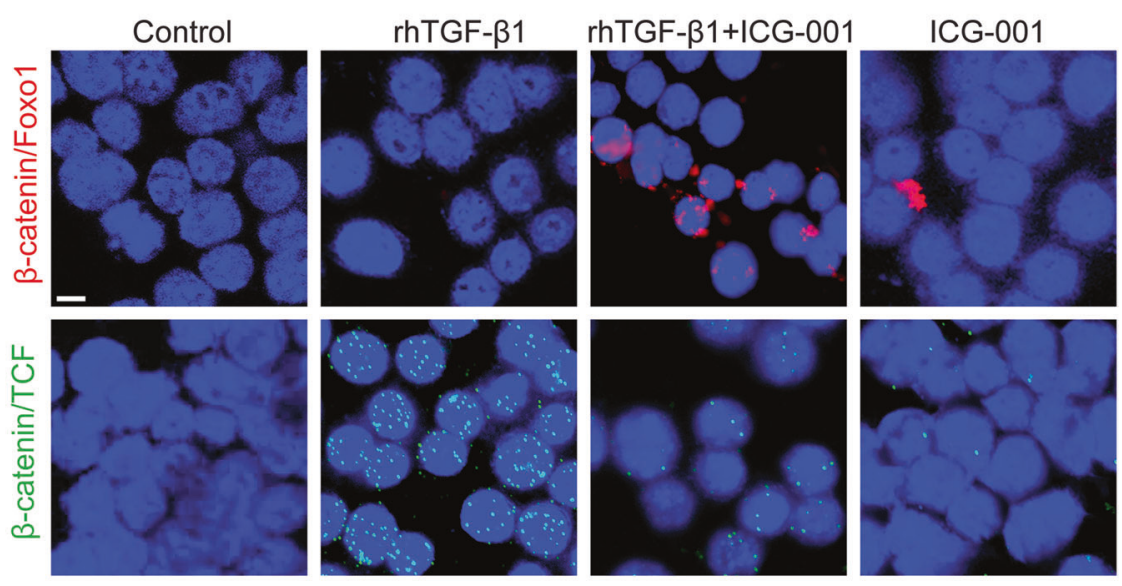
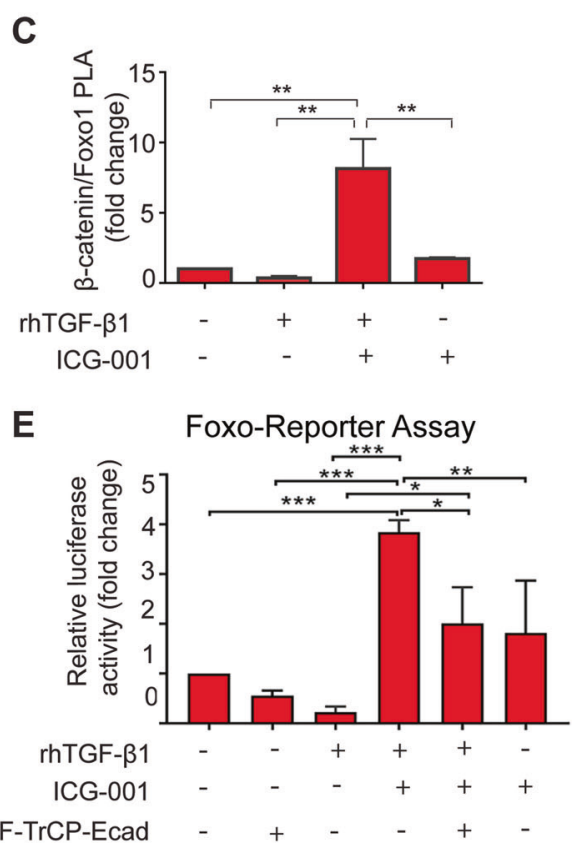

D

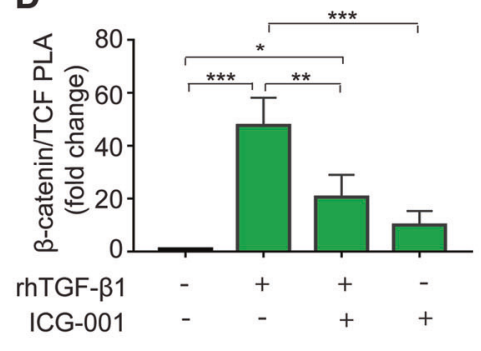

F

TOP-Flash Assay

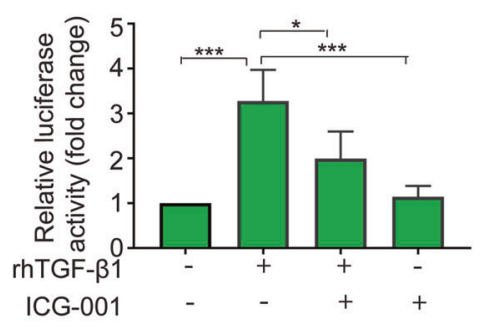




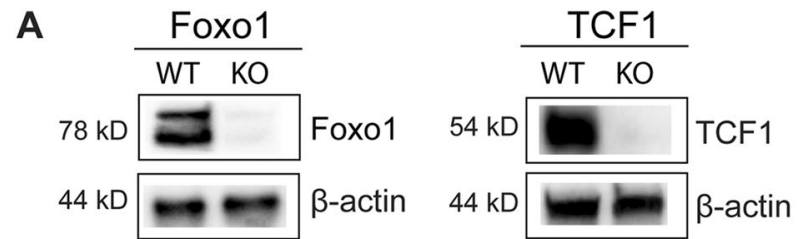

B

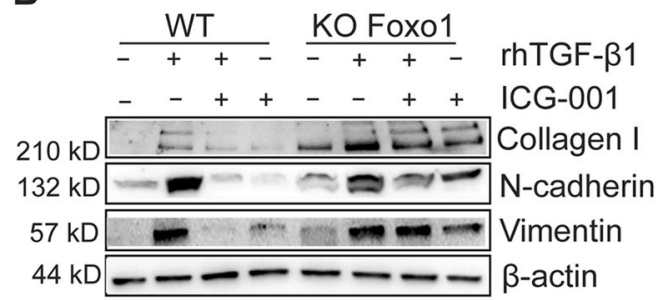

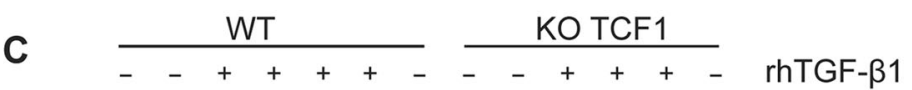
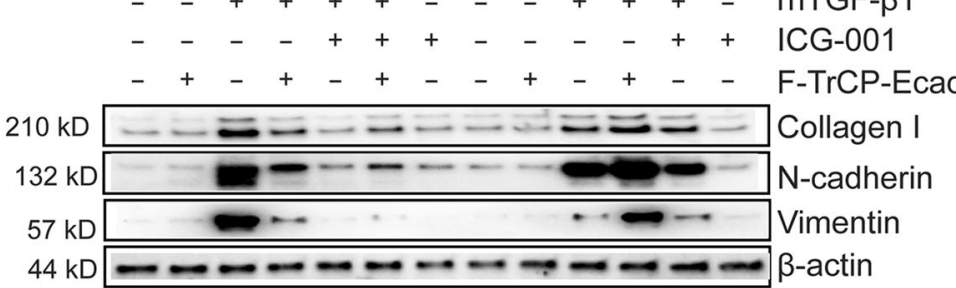

D Collagen I
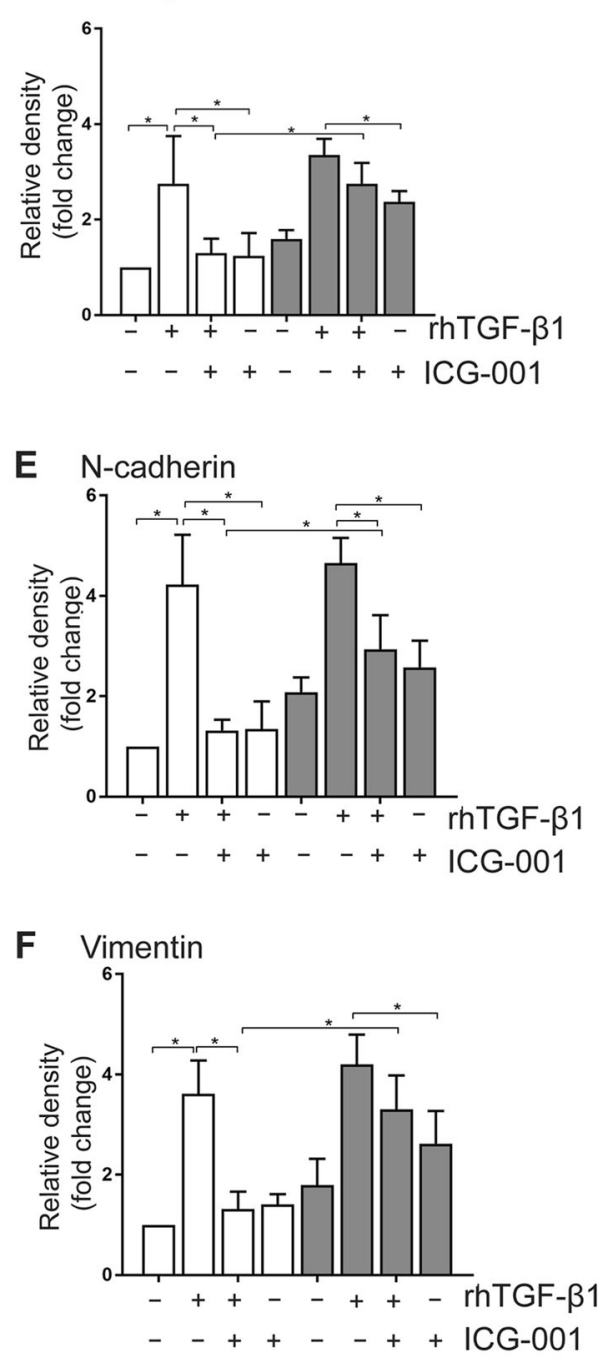
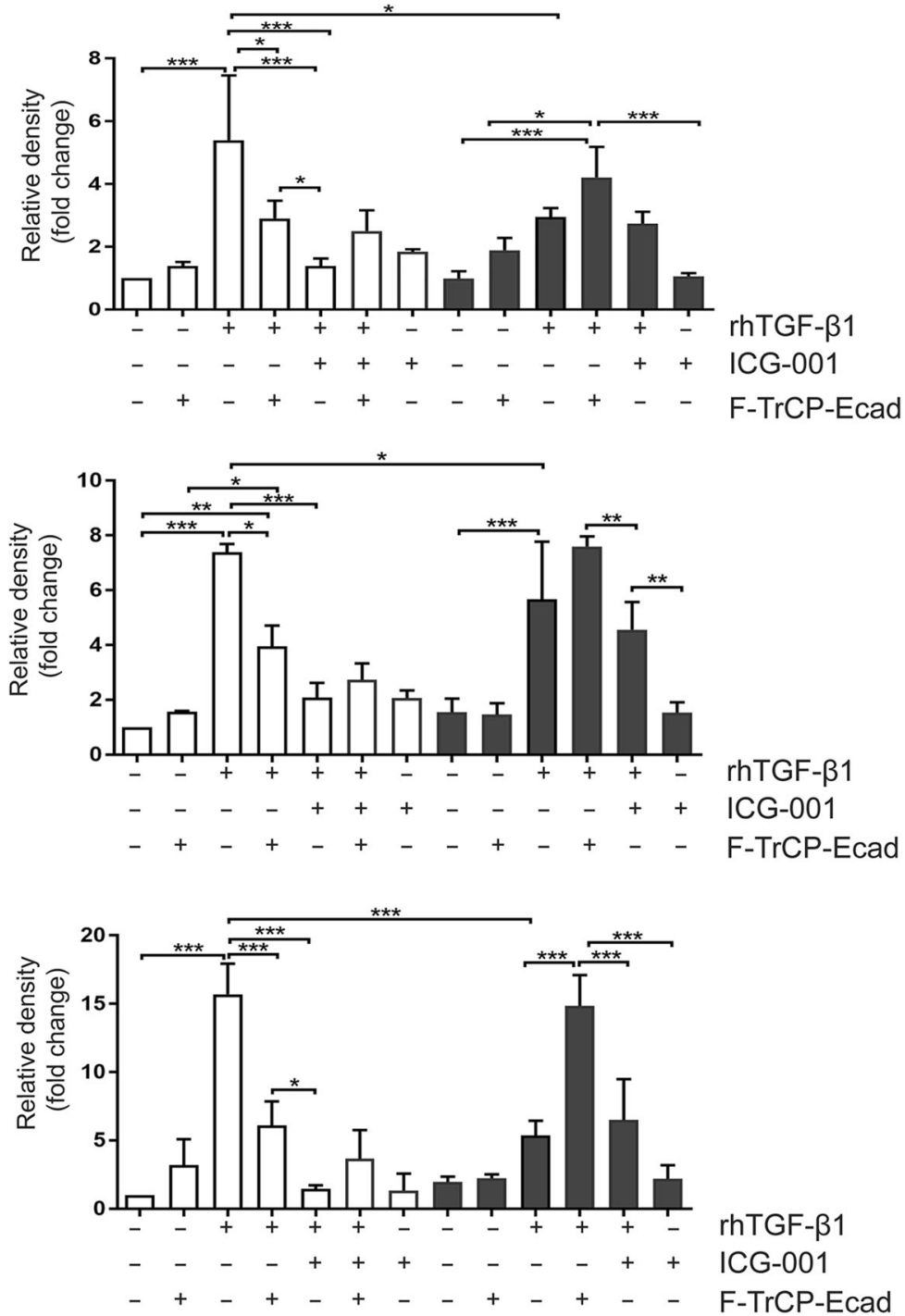
Fig. 3 Collagen I, N-cadherin and vimentin expression in wild-type, Foxo1 KO and TCF1 KO C1.1 cells. a Foxo1 KO and TCF1 KO by CRISPR/cas9 in C1.1 cells was confirmed by western blot analysis. $\mathbf{b}$ Representative Western blots of collagen I, N-cadherin and vimentin compared with $\beta$-actin control in lysate of untreated or treated wildtype (WT) and Foxo1 KO C1.1 cells. c Representative Western blot of collagen I, N-cadherin and vimentin compared with $\beta$-actin control in lysate of WT and TCF1 KO C1.1 cells with various treatments. Quantitation of fold change in relative density of $\mathbf{d}$ collagen I, e Ncadherin and $\mathbf{f}$ vimentin in WT (white columns), Foxo1 KO (red columns) and TCF1 KO (green columns) with various treatments described. The relative density of WT control was arbitrarily defined as one. Results are representative of three independent experiments. Results are shown as mean \pm SEM. Statistical significance was determined by one-way ANOVA followed by Tukey post hoc test. $* P<0.05$

Taken together, our results showed that promotion of $\beta$ catenin/Foxo1, in addition to inhibition of $\beta$-catenin/TCF, protects against TGF- $\beta 1$-induced profibrotic changes.

Immunofluorescence staining confirmed the findings of Western blot analysis of vimentin. As shown in Fig. 4, combined treatment of rhTGF- $\beta 1$ and ICG-001 in wildtype $\mathrm{C} 1.1$ cells reduced vimentin expression. In Foxo1 KO C1.1 cells, the inhibitory effect of ICG-001 on rhTGF- $\beta 1$-induced vimentin expression was reduced. The lesser reduction of TGF- $\beta$-induced vimentin expression is consistent with the absence $\beta$-catenin/Foxo, whereas in WT cells, ICG-001 inhibition of $\beta$-catenin/ TCF also increases $\beta$-catenin/Foxo, and thereby further reduces vimentin expression. In TCF1 KO cells, rhTGF- $\beta 1$-induced vimentin expression was suppressed (Fig. 4).

Collectively, the results demonstrate that ICG-001, an inhibitor of $\beta$-catenin/TCF, along with rhTGF- $\beta 1$ promotes activation of $\beta$-catenin/Foxo1 in $\mathrm{C} 1.1$ cells and protects against TGF- $\beta 1$-induced profibrotic proteins.

\section{rhTGF- $\beta 1$ and ICG-001 reduces kidney fibrosis in obstructed kidney}

Having demonstrated the protective role of $\beta$-catenin/Foxo1 in $\mathrm{C} 1.1$ cells by inhibiting $\beta$-catenin/TCF via ICG-001 and rhTGF- $\beta 1$, we then sought to determine if $\beta$-catenin/Foxo1 protects against kidney fibrosis in vivo. To this end, ICG001 was administered intraperitoneally to Foxp3 GFP mice after unilateral ureteral obstruction (UUO) at dosages of 5 $\mathrm{mg} / \mathrm{kg}$ body weight daily and rhTGF- $\beta 1$ at $50 \mu \mathrm{g} / \mathrm{kg}$ body weight every two days. We evaluated the effect of rhTGF$\beta 1$ and ICG-001 treatment on kidney fibrosis using collagen expression, specifically that of collagen I, collagen III and collagen IV. Administration of rhTGF- $\beta 1$ and ICG-001 significantly reduced interstitial staining for collagen I, collagen III and collagen IV, as compared to that of untreated UUO mice (Fig. 5b) which was confirmed by Western blot (Supplemental Fig. 2). Importantly, mice administered rhTGF- $\beta 1$ and ICG-001 showed greater attenuation of these morphologic lesions than seen with
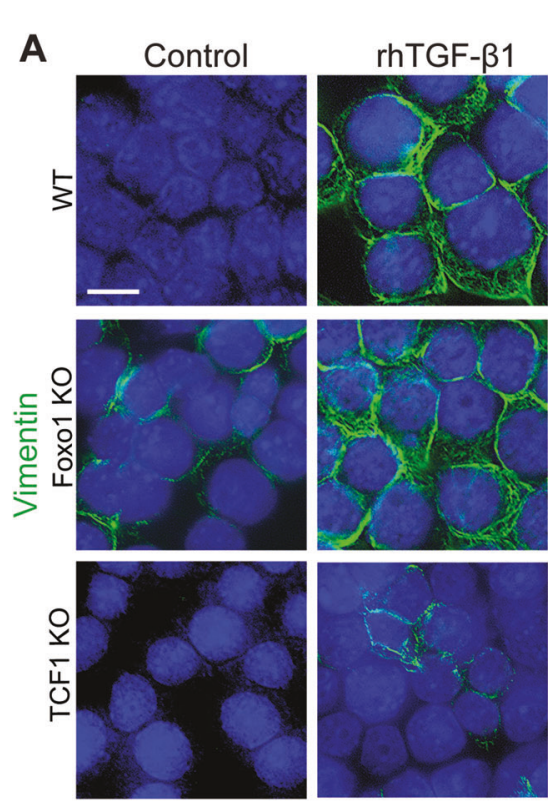

Fig. 4 Vimentin expression in wild-type, Foxo1 KO and TCF1 KO C1.1 cells. a Representative immunofluorescence images of vimentin staining in wild-type, Foxo1 KO and TCF1 KO C1.1 cells, untreated (control) or treated with rhTGF- $\beta 1$, or rhTGF- $\beta 1$ plus ICG-001, or ICG-001 alone. Nuclei were stained with DAPI. Original

rhTGF- $\beta 1+$
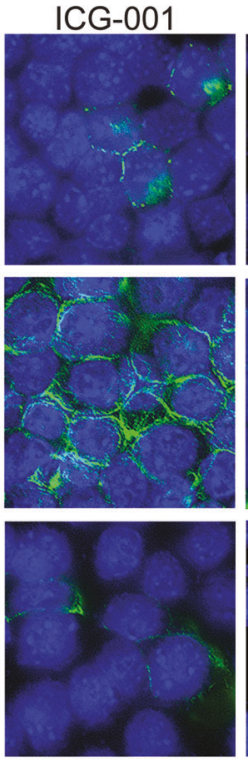
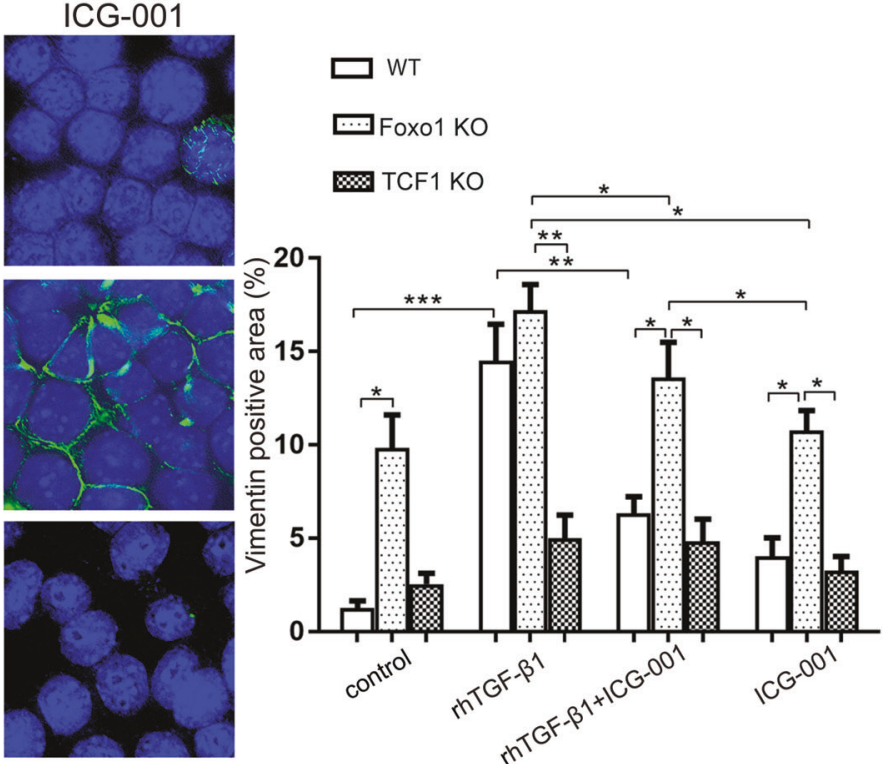

magnification, X60. Scale bar, $40 \mu \mathrm{m}$. Quantitation of positive staining area of vimentin in WT, Foxo1 KO and TCF1 KO C1.1 cells with various treatments was compared by one-way ANOVA followed by Tukey post hoc test. Results are shown as mean \pm SEM $(n=4) . * P<$ $0.05, * * P<0.01, * * * P<0.001$ 

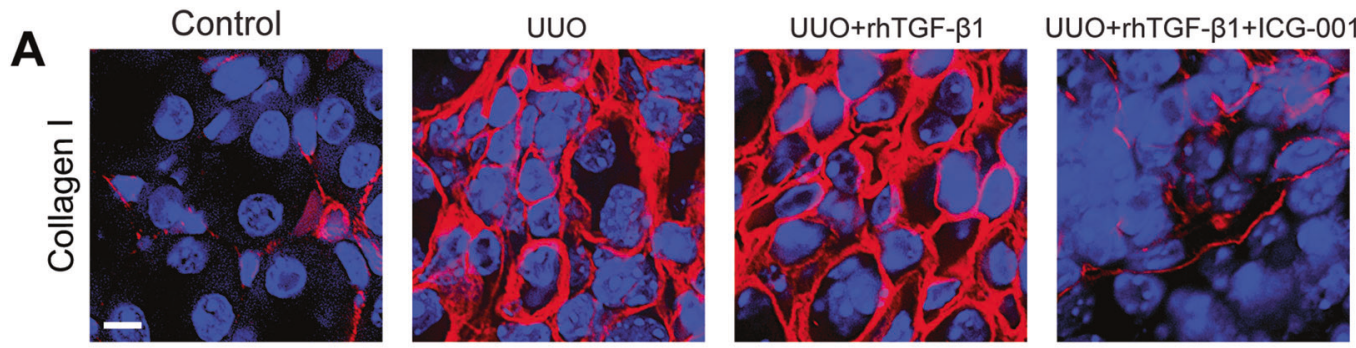

UUO+ICG-001
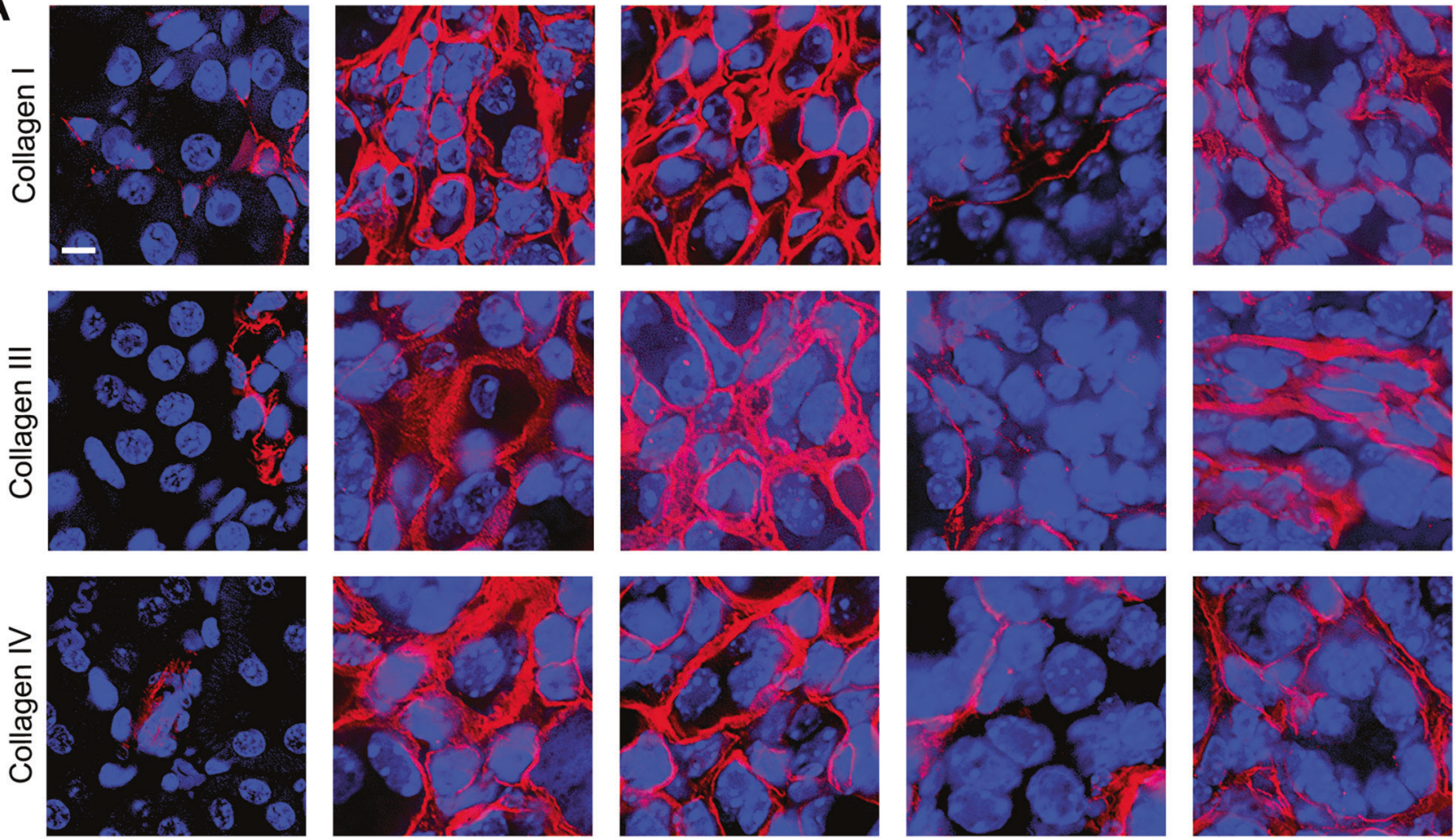

B

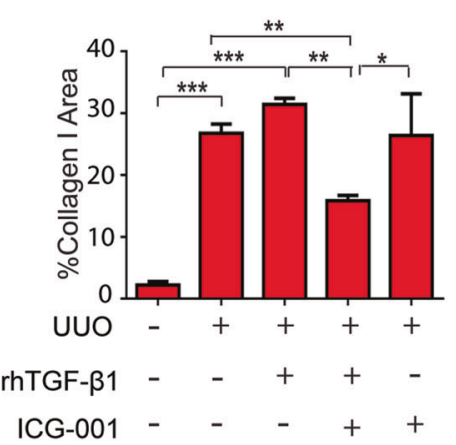

Fig. 5 Kidney fibrosis in UUO mice. a Representative immunofluorescence images of collagen I, collagen III and collagen IV staining. Nuclei were stained with DAPI. Original magnification, X60. Scale bar, $10 \mu \mathrm{m}$. b Quantitation data of collagen I, collagen III and

ICG-001 treatment alone. This is consistent with our previous study [10], which showed that combined treatment with rhTGF- $\beta 1$ and ICG-001 reversed the anti-inflammatory effects of rhTGF- $\beta 1$ by a $\beta$-catenin/Foxo1-dependent increase in Tregs, while the $\beta$-catenin/TCF-dependent fibrosis was inhibited by ICG001. However, the current in vitro study showed that the combined treatment also protected profibrotic changes directly in tubular epithelial cells in a $\beta$-catenin/Foxo1-dependent manner, an additional mechanism which explains the greater protection of the combined treatment. To investigate this further, we examined $\beta$-catenin/Foxo1 and $\beta$-catenin/TCF interactions in the UUO kidney.

\section{Shifting of $\beta$-catenin from TCF to Foxo 1 by rhTGF- $\beta 1$ and ICG-001 in obstructed injury}

To examine whether $\beta$-catenin/Foxo1 underlies the protection of kidney fibrosis in UUO mice by combined treatment with rhTGF- $\beta 1$ and ICG-001, we employed PLA. PLA analysis of kidney sections showed a significantly higher PLA signal for $\beta$-catenin/Foxo1 predominantly in tubules (shown by the differential interference contrast (DIC) images of tubular morphology outlined in Fig. 6a) of UUO mice treated with rhTGF- $\beta 1$ and ICG-001 compared with all other groups (Fig. 6a). The PLA results were supplemented by immunofluorescence staining for $\beta$-catenin and Foxo1 in 
A

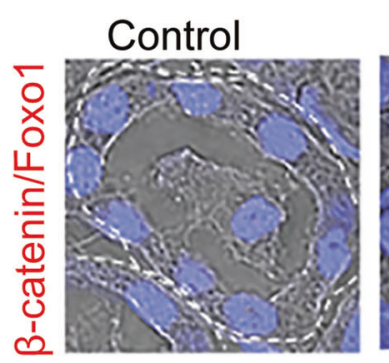

B

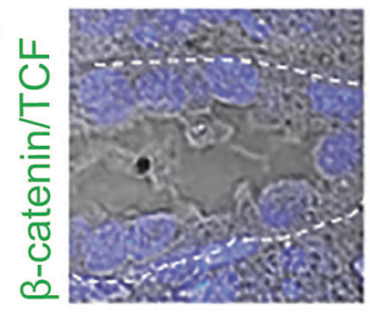

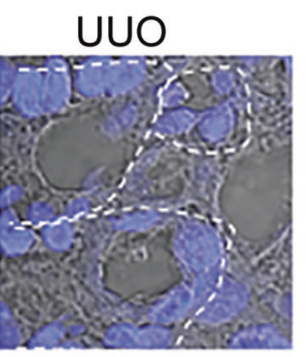
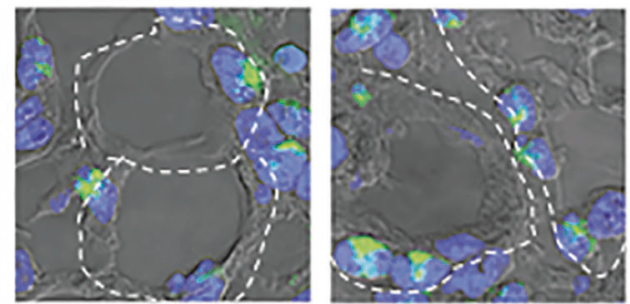

UUO+rhTGF- $\beta 1+$

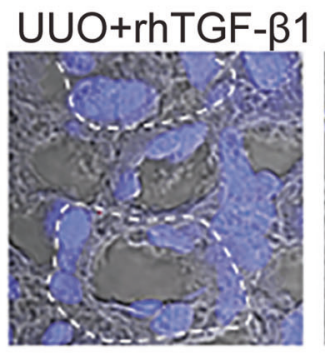

ICG-001
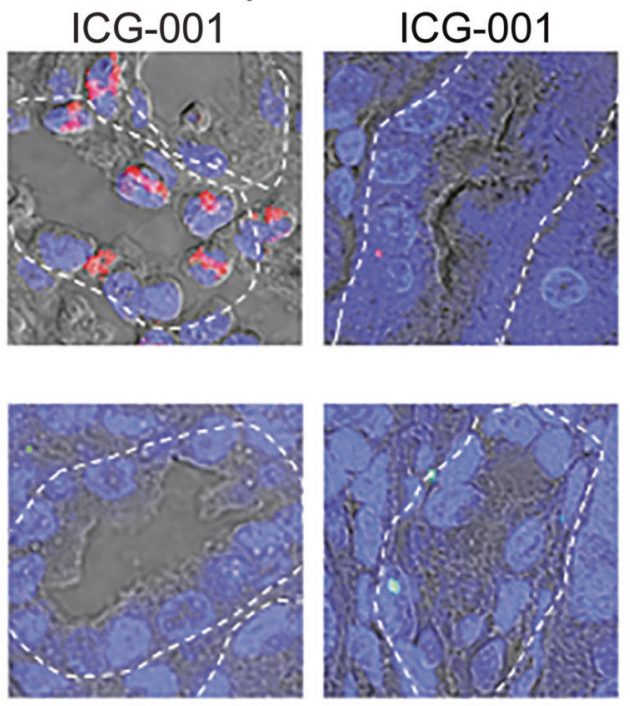

C

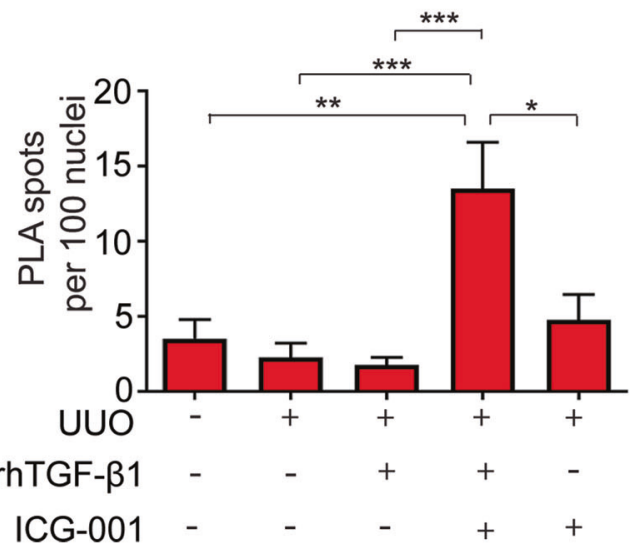

Fig. 6 PLA analysis of $\beta$-catenin/Foxo1 and $\beta$-catenin/TCF interactions in tubular cells in UUO kidney. a Representative $\beta$-catenin/ Foxo1 (red spot) and b $\beta$-catenin/TCF (green spot) interaction in kidney sections of control, untreated UUO, and UUO mice treated with rhTGF- $\beta 1$, rhTGF- $\beta 1$ and ICG-001, or ICG-001 only. Nuclei were stained with DAPI. Fluoroscence images were merged with

tubular cells of UUO mice (Supplemental Fig. 3). $\beta$-catenin/ TCF was significantly increased in the kidney tubular cells of UUO mice, and further increased with rhTGF- $\beta 1$ only treatment, but significantly reduced by combined treatment with rhTGF- $\beta 1$ and ICG-001 (Fig. 6b). These results provide in vivo evidence that co-administration of rhTGF- $\beta 1$ and ICG-001 in UUO mice indeed shifted $\beta$-catenin from TCF to Foxo in protecting against fibrosis.

\section{Discussion}

Interaction between transcription factors is recognized as a new mechanism for diverse functions of cytokines such as

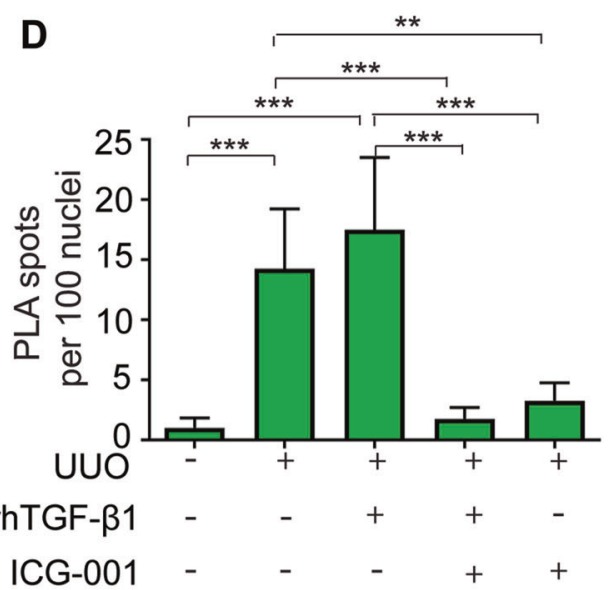

differential interference contrast (DIC) images to show the localization of PLA signals in tubular cells (indicated by broken lines). Original magnification, X60. c, d Quantitation data of PLA signals by one-way ANOVA followed by Tukey post hoc test. Results are shown as mean \pm SEM $(n=6) . * P<0.05, * * P<0.01, * * * P<0.001$

TGF- $\beta$. TCF and Foxo are two transcription co-factors that bind to $\beta$-catenin in competition. Depending on the key binding partner of $\beta$-catenin, for example TCF or Foxo, the response of target cells to TGF- $\beta$ signaling can be quite different, even in opposite directions [6, 23, 24]. Therefore, it is important to identify the various key transcription cofactors that determine a cytokine's function. Activation of $\beta$-catenin/TCF targeted genes is a common feature of fibrosis [25], which promotes proliferation of myofibroblasts and expression of fibrotic genes [26]. ICG-001 has been shown effective in inhibition of $\beta$-catenin/TCF-mediated fibrosis [6, 27, 28]. Our previous study proved that inhibition of $\beta$-catenin/TCF not only prevented $\beta$-catenin/TCF-mediated fibrosis in kidney, but also shifted 
$\beta$-catenin/TCF to $\beta$-catenin/Foxo1 which promoted TGF- $\beta$ 's anti-inflammatory effects via upregulation of Tregs [6]. This novel observation explains how conflicting profibrotic and anti-inflammatory roles of TGF- $\beta$ can be dissociated to maximize the therapeutic effect of targeting TGF- $\beta$. However, whether $\beta$-catenin/Foxo1 protects directly against profibrotic effects in tubular cells in addition to its antiinflammatory function was unknown and not investigated in that study. In the current study, we used CRISPR/cas9mediated Foxo and TCF knockout in vitro, and showed a novel protective role for $\beta$-catenin/Foxo against profibrotic signaling of TGF- $\beta$. In addition, rhTGF- $\beta 1$ and ICG-001 was found to be protective against kidney fibrosis in a murine model of UUO. Thus, we showed that binding of $\beta$ catenin to Foxo not only diverted the limited pool of $\beta$ catenin away from TCF to inhibit fibrosis, but also that $\beta$ catenin/Foxo per se was protective against fibrosis.

In this study, we characterized for the first time $\beta$-catenin/Foxo1 and $\beta$-catenin/TCF expression in human kidney biopsies by PLA and their association with kidney fibrosis. Our findings in tubular cells of patient biopsies lend strong support to a protective role of $\beta$-catenin/Foxo1 against kidney fibrosis. Kidney fibrosis in biopsies of patients with diabetic nephropathy, IgA nephropathy, hypertensive nephropathy, FSGS, MCGN, medullary cystic diseases and kidney transplant exhibited a strong positive correlation with levels of $\beta$-catenin/TCF and inverse correlation with $\beta$ catenin/Foxo1. The reciprocal relationship between levels of $\beta$-catenin/TCF and $\beta$-catenin/Foxo1 are consistent with competition between Foxo1 and TCF in binding to $\beta$ catenin. PLA is an established method to visualize binding or interaction between proteins; here we have used it for the first time to determine interactions between $\beta$-catenin/TCF and $\beta$-catenin/Foxo1 that are pivotal to progression of human disease. Importantly, the same antibodies were used to identify $\beta$-catenin/Foxo1 and $\beta$-catenin/TCF interactions in murine tissues and human kidney biopsy samples, not only proving the conservation of protein structure of those transcription factors between human and mouse, but also providing evidence for the relevance of findings in the mouse model to human CKDs.

These studies are the first to examine $\beta$-catenin/Foxo1 and $\beta$-catenin/TCF expression by PLA in both in vitro and in vivo experiments. The PLA analysis in both in vitro and in vivo experiments provides direct evidence for the promotion of $\beta$-catenin/Foxo through inhibition of $\beta$-catenin/ TCF by ICG-001 together with rhTGF- $\beta 1$ treatment. Collectively, human, and in vitro and in vivo animal data demonstrate a pivotal role for $\beta$-catenin/Foxo in protecting against kidney fibrosis.

Importantly this study was able to prove the protective role of $\beta$-catenin/Foxo1 by using CRISPR/cas9 KO of Foxo1 or TCF in C1.1 cells. By CRISPR/cas9 knockout of
Foxo1, we identified the dependence on Foxo1 of protection against TGF- $\beta$ induced profibrotic changes in $\mathrm{C} 1.1$ cells. Meanwhile, we also identified the necessity of $\beta$-catenin for Foxo activity in protecting against TGF- $\beta$-induced profibrotic changes in tubular cells by altering $\beta$-catenin levels using F-TrCP-Ecad in wild-type and TCF KO C1.1 cells. Thereby, a $\beta$-catenin/Foxo1-dependent protective effect in tubular epithelial cells was established. In addition, we showed a reduction of kidney fibrosis in UUO mice treated with rhTGF- $\beta 1$ when combined with ICG-001, accompanied with upregulation of $\beta$-catenin/Foxo1 in tubules as an additional mechanism for the greater protection by rhTGF- $\beta 1$ and ICG001 than by ICG001 alone treatment.

In this study we have demonstrated a $\beta$-catenin/Foxo1dependent protective effect in tubular epithelial cells indirectly by deletion of Foxo1. Ideally, a selective $\beta$-catenin/ Foxo1 inhibitor is required to prove dependence on $\beta$ catenin/Foxo in protection against TGF- $\beta 1$-induced profibrotic changes. However, no specific $\beta$-catenin/Foxo inhibitor have been developed so far. Alternatively, we used $\beta$ catenin degradation (F-TrCP-Ecad) in absence of TCF (TCF1 KO C1.1 cells) to prevent Foxo1 binding to $\beta$ catenin, to prove the protective role of Foxo1 binding to $\beta$ catenin.

In summary, our study shows that $\beta$-catenin/Foxo1 protects against TGF- $\beta$ induced profibrotic effects directly in tubular epithelial cells, independent of its role in Tregs and may serve as a novel target for treatment of human kidney fibrosis.

Acknowledgements The project was supported by Project Grants from the National Health and Medical Research Council (NHMRC) of Australia (APP1046647 \& 1141235). PR was funded by an Australian Government Research Training Program Scholarship.

Author contributions All authors participated in the design, interpretation of the studies and review of the manuscript. PR performed the majority of the experiments, analysed and interpreted data, and wrote the majority of the manuscript. MP, HW, and XQ performed some of the animal experiments and tissue collection. HY analyzed microscopy images. YY and XR performed some immunofluorescence staining. MK analyzed PLA data in human kidney biopsies. SA, YMW, MH, TC, and VL participated in experimental design and reviewed the manuscript. $\mathrm{CP}$ and $\mathrm{BN}$ provided human biopsies and clinical data. QC, YW, and GZ assisted in animal experiments. GZ designed and interpreted the experiments, oversaw all the experiments, and reviewed all the data and the manuscript. DH designed the experiments, and critically reviewed the data and the manuscript.

\section{Compliance with ethical standards}

Conflict of interest The authors declare that they have no conflict of interest.

Publisher's note: Springer Nature remains neutral with regard to jurisdictional claims in published maps and institutional affiliations. 
Open Access This article is licensed under a Creative Commons Attribution 4.0 International License, which permits use, sharing, adaptation, distribution and reproduction in any medium or format, as long as you give appropriate credit to the original author(s) and the source, provide a link to the Creative Commons license, and indicate if changes were made. The images or other third party material in this article are included in the article's Creative Commons license, unless indicated otherwise in a credit line to the material. If material is not included in the article's Creative Commons license and your intended use is not permitted by statutory regulation or exceeds the permitted use, you will need to obtain permission directly from the copyright holder. To view a copy of this license, visit http://creativecommons. org/licenses/by/4.0/.

\section{References}

1. Zhou D, Fu H, Zhang L, Zhang K, Min Y, Xiao L, et al. Tubulederived Wnts are required for fibroblast activation and kidney fibrosis. J Am Soc Nephrol. 2017;28:2322-36.

2. He J, Xu Y, Koya D, Kanasaki K. Role of the endothelial-tomesenchymal transition in renal fibrosis of chronic kidney disease. Clin Exp Nephrol. 2013;17:488-97.

3. Border WA, Noble NA. Transforming growth factor beta in tissue fibrosis. N Engl J Med. 1994;331:1286-92.

4. Blobe GC, Schiemann WP, Lodish HF. Role of transforming growth factor beta in human disease. $\mathrm{N}$ Engl $\mathrm{J}$ Med. 2000;342:1350-8.

5. Werner S, Grose R. Regulation of wound healing by growth factors and cytokines. Physiol Rev. 2003;83:835-70.

6. Qiao X, Rao P, Zhang Y, Liu L, Pang M, Wang H, et al. Redirecting TGF-beta signaling through the beta-catenin/foxo complex prevents kidney fibrosis. J Am Soc Nephrol. 2018;29:557-70.

7. Angers S, Moon RT. Proximal events in Wnt signal transduction. Nat Rev Mol Cell Biol. 2009;10:468-77.

8. Hao S, He W, Li Y, Ding H, Hou Y, Nie J, et al. Targeted inhibition of beta-catenin/CBP signaling ameliorates renal interstitial fibrosis. J Am Soc Nephrol. 2011;22:1642-53.

9. Surendran K, Schiavi S, Hruska KA. Wnt-Dependent $\beta$-Catenin Signaling Is Activated after Unilateral Ureteral Obstruction, and Recombinant Secreted Frizzled-Related Protein 4 Alters the Progression of Renal Fibrosis. J Am Soc Nephrol. 2005;16:2373-84.

10. Accili D, Arden KC. FoxOs at the crossroads of cellular metabolism, differentiation, and transformation. Cell 2004;117:421-6.

11. Greer EL, Brunet A. FOXO transcription factors at the interface between longevity and tumor suppression. Oncogene. 2005;24: 7410-25.

12. Graham JA, Fray M, de Haseth S, Lee KM, Lian MM, Chase CM, et al. Suppressive regulatory $\mathrm{T}$ cell activity is potentiated by glycogen synthase kinase 3 \{beta\} inhibition. J Biol Chem. 2010;285:32852-9.
13. Bowerman B. Cell biology. Oxidative stress and cancer: a betacatenin convergence. Science 2005;308:1119-20.

14. Essers MA, de Vries-Smits LM, Barker N, Polderman PE, Burgering BM, Korswagen HC. Functional interaction between betacatenin and FOXO in oxidative stress signaling. Science 2005;308:1181-4.

15. Wuthrich RP, Glimcher LH, Yui MA, Jevnikar AM, Dumas SE, Kelley VE. MHC class II, antigen presentation and tumor necrosis factor in renal tubular epithelial cells. Kidney Int. 1990;37:783-92.

16. Cong F, Zhang J, Pao W, Zhou P, Varmus H. A protein knockdown strategy to study the function of beta-catenin in tumorigenesis. BMC Mol Biol. 2003;4:10.

17. Tian X, Zhang J, Tan TK, Lyons JG, Zhao H, Niu B, et al. Association of beta-catenin with P-Smad3 but not LEF-1 dissociates in vitro profibrotic from anti-inflammatory effects of TGF-beta1. J Cell Sci. 2013;126:67-76.

18. Khushi M, Napier CE, Smyth CM, Reddel RR, Arthur JW. MatCol: a tool to measure fluorescence signal colocalisation in biological systems. Sci Rep. 2017;7:8879.

19. Lahl K, Loddenkemper C, Drouin C, Freyer J, Arnason J, Eberl G, et al. Selective depletion of Foxp3+ regulatory $\mathrm{T}$ cells induces a scurfy-like disease. J Exp Med. 2007;204:57-63.

20. Moriyama T, Kawada N, Ando A, Yamauchi A, Horio M, Nagata $\mathrm{K}$, et al. Up-regulation of HSP47 in the mouse kidneys with unilateral ureteral obstruction. Kidney Int. 1998;54:110-9.

21. Soderberg O, Gullberg M, Jarvius M, Ridderstrale K, Leuchowius $\mathrm{KJ}$, Jarvius J, et al. Direct observation of individual endogenous protein complexes in situ by proximity ligation. Nat Methods. 2006;3:995-1000.

22. Henderson WR Jr, Chi EY, Ye $X$, Nguyen C, Tien YT, Zhou B, et al. Inhibition of Wnt/beta-catenin/CREB binding protein (CBP) signaling reverses pulmonary fibrosis. PNAS. 2010; 107:14309-14.

23. Hoogeboom D, Essers MA, Polderman PE, Voets E, Smits LM, Burgering BM. Interaction of FOXO with beta-catenin inhibits betacatenin/T cell factor activity. J Biol Chem. 2008;283:9224-30.

24. Almeida M, Han L, Martin-Millan M, O’Brien CA, Manolagas SC. Oxidative stress antagonizes Wnt signaling in osteoblast precursors by diverting beta-catenin from $\mathrm{T}$ cell factor- to forkhead box Omediated transcription. J Biol Chem. 2007;282:27298-305.

25. Lam AP, Gottardi CJ. $\beta$-catenin signaling: a novel mediator of fibrosis and potential therapeutic target. Curr Opin Rheumatol. 2011;23:562-7.

26. Katoh M, Katoh M. WNT signaling pathway and stem cell signaling network. Clin Cancer Res. 2007;13:4042-5.

27. Arensman MD, Telesca D, Lay AR, Kershaw KM, Wu N, Donahue TR, et al. The CREB-binding protein inhibitor ICG-001 suppresses pancreatic cancer growth. Mol Cancer Ther. 2014;13:2303-14.

28. Eguchi M, Nguyen C, Lee SC, Kahn M. ICG-001, a novel small molecule regulator of TCF/beta-catenin transcription. Med Chem. 2005;1:467-72. 